\title{
Small bowel tumours: yield of enteroscopy
}

\author{
B S Lewis, A Kornbluth, J D Waye
}

\begin{abstract}
A total of 258 patients with obscure gastrointestinal bleeding were referred for small bowel enteroscopy, a procedure which allows endoscopic evaluation of most of the small intestine. A small bowel tumour was found in $\mathbf{5 \%}$ of patients. In $\mathbf{5 0 \%}$ of patients no diagnosis could be made, but when the cause of obscure bleeding was discovered small bowel tumours were the single most common lesion in patients younger than $\mathbf{5 0}$ years. Small bowel tumours causing gastrointestinal bleeding may remain undetected despite extensive diagnostic evaluation. We conclude that small bowel tumours are the most common cause of obscure gastrointestinal bleeding in patients less than 50 years of age. Small bowel enteroscopy is diagnostic of small bowel tumours even when all previous diagnostic studies, including enteroclysis and angiography, are negative.
\end{abstract}

Small bowel enteroscopy is a new endoscopic examination of the small intestine that can be performed within eight hours on an ambulatory basis. Small bowel enteroscopy is especially useful in patients with obscure gastrointestinal bleeding. Early experience in 60 of these patients has been reported previously. ${ }^{3}$ We now present our data on small bowel tumours in 258 patients referred for enteroscopy.

\section{Methods}

The endoscope used is $2560 \mathrm{~mm}$ long and has a 5 mm tip diameter (SIF-SW, Olympus, New Hyde Park, New York, USA). It has a forward view of $120^{\circ}$ but no deflectional or therapeutic capability. ${ }^{4}$ The small bowel enteroscope has two internal channels, one for air inflation and one for balloon at the instrument's tip that acts as a bolus for peristaltic action. The technique of small bowel enteroscopy has been described previously. ${ }^{5}$ Initially, the enteroscope is passed transnasally into the stomach. A paediatric colonoscope is then passed orally and advanced into the jejunum, an examination called 'push' enteroscopy. The paediatric colonoscope or 'push' enteroscope is then withdrawn into the stomach and used to position the small bowel enteroscope in the small intestine. A suture affixed to the enteroscope's tip is grasped and both instruments are advanced in the jejunum. Peristalsis then carries the small bowel enteroscope distally. Passage time averages eight hours with $77 \%$ of examinations reaching the distal ileum or beyond into the colon. Endoscopic examination of the small intestine is performed on instrument withdrawal, which averages $45-60$ minutes.

A total of 258 patients with obscure gastro-
TABLE I Patient characteristics

No of patients 258

Mean age (range) (years) 63.4 (17-89)

Median (range) No of months of bleeding 12 ( 10 days-20 years) Median (range) No of units of blood transfused $10(0-200)$

intestinal bleeding were referred for small bowel enteroscopy. Patient characteristics are described in Table I. All patients had undergone an extensive diagnostic evaluation with an average of 11 diagnostic procedures per patient including upper endoscopy, colonoscopy, upper gastrointestinal series with small bowel follow through, and barium enema, as well as bleeding scans, angiography, and enteroclysis in some patients. Enteroscopy was performed in all patients without complication. Comparisons between groups were made with the two tailed Student's $t$ test for parametric data and with the MannWhitney U test for non-parametric data. Ratios between groups were compared with the $\chi^{2}$ test with Yates's correction.

\section{Results}

Thirteen small bowel tumours were discovered in the 258 patients undergoing enteroscopy. The location and pathology of the tumours resected are shown in Figure 1. There were nine malignant and four benign tumours. Five of the 13 tumours were located within the fourth portion of the duodenum or within the first two feet of the jejunum and were within reach of the paediatric colonoscope passed orally. The remaining eight tumours were located distally and discovered by small bowel enteroscopy, Six

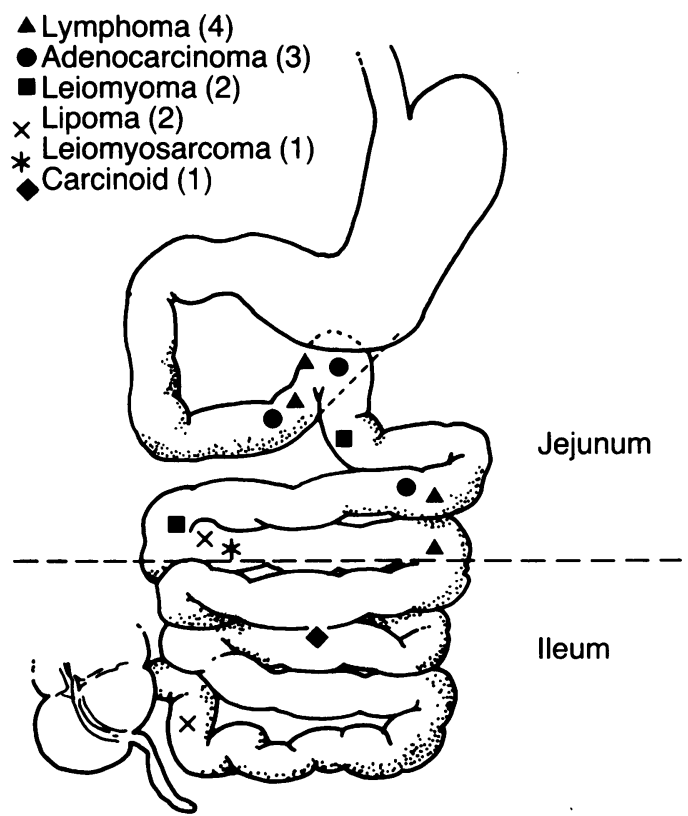

Figure 1: Location of small bowel tumours.
Gastroenterology, Mount Sinai Medical Center, B S Lewis A Kornbluth J D Waye

Blair S Lewis, MD, 650 Park Avenue, New York NY 10021

Accepted for publication

10 September 1990 
Figure 2: $(A)$ Incidence of small bowel tumours by age. (B) Arteriovenous malformations in the small bowel by age.
(A)

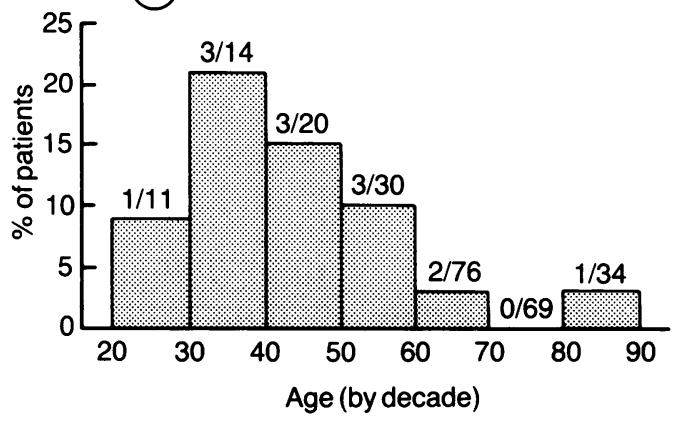

pre-examination enteroclysis studies in four patients failed to show these small bowel tumours. In seven patients angiography before small bowel enteroscopy was also nondiagnostic.

When patients with obscure bleeding were divided according to age, $3 \%(6 / 207)$ of patients over the age of 50 years had a small bowel tumour, while $14 \%(7 / 51)$ under 50 had a small bowel tumour $(p=0 \cdot 006)$. The incidence of small bowel tumours related to age is shown in Figure $2 \mathrm{~A}$. The age/tumour relation contrasts distinctly with the major diagnostic group, arteriovenous malformations, which increased with increasing age into the ninth decade (Fig 2B). Arteriovenous malformations of the small intestine were the most common finding at enteroscopy and occurred in $40 \%$ of patients (Table II). When patients with small bowel tumours are compared with patients with arteriovenous malformations only age and the number of units of blood transfused distinguished these two groups (Table III). The mean age of patients with a tumour was 51.4 years compared with 69 years for patients with arteriovenous malformations $(p=0 \cdot 001)$. The mean number of units of blood transfused in the tumour patients was six compared with 14 in the other group $(p=0.002)$.

There was no difference in the pattern of bleeding, whether continuous or intermittent, with visible blood or occult, between the two groups of patients. None of the patients with a small bowel tumour had any sign or symptom

TABLE II Small bowel enteroscopy findings in 258 patients

\begin{tabular}{lc}
\hline Diagnosis & $\begin{array}{l}\text { No(\%) of } \\
\text { patients }\end{array}$ \\
\hline Arteriovenous malfunctions & $102(40)$ \\
Tumours & $13(5)$ \\
Other (ulcers, Meckel's diverticum, varices) & $13(5)$ \\
No finding & $130(50)$
\end{tabular}

TABLE III Clinical features of patients with tumours of the small bowel compared with patients with arteriovenous malformations of the small bowel

\begin{tabular}{llll}
\hline & Tumours & $\begin{array}{l}\text { Arteriovenous } \\
\text { malformations }\end{array}$ & Significance \\
\hline $\begin{array}{l}\text { No of patients } \\
\text { Mean age (years) }\end{array}$ & 13 & 102 & \\
$\begin{array}{l}\text { No of months of } \\
\text { bleeding }\end{array}$ & 12 & $69 \cdot 0$ & $\mathrm{p}=0.001$ \\
$\begin{array}{c}\text { No of units of blood } \\
\text { transfused }\end{array}$ & 6 & 18 & $\mathrm{NS}$ \\
$\begin{array}{c}\text { No of diagnostic } \\
\text { examinations }\end{array}$ & $10 \cdot 8$ & 11 & $\mathrm{p}=0.002$ \\
$\begin{array}{c}\text { Type of bleeding: } \\
\text { Frank }\end{array}$ & $8 / 13(62 \%)$ & $65 / 102(64 \%)$ & $\mathrm{NS}$ \\
Occult & $5 / 13(38 \%)$ & $37 / 102(36 \%)$ & $\mathrm{NS}$ \\
\hline
\end{tabular}

NS $=$ not significant.

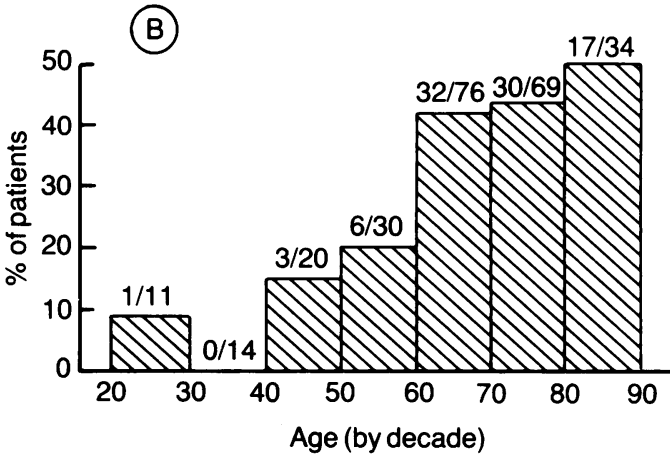

other than gastrointestinal bleeding to suggest the presence of a tumour.

Five per cent of patients were grouped as miscellaneous causes of bleeding discovered at enteroscopy. These diagnoses included Meckel's diverticulum, unsuspected Crohn's disease, aortoileal fistula, ulcerative jejunitis, and jejunal varices.

All 13 patients found to have a small bowel tumour underwent surgical resection; $62 \%(8 /$ 13) remain disease free at a mean follow up of 10 months. Two patients had metastatic disease at operation and an additional two patients had metastatic disease detected at four and 12 months after operation. One patients, an 89 year old man, died of a myocardial infarction four days after operation. Overall, 12 of 13 patients are alive at a mean follow up of nine months. In $92 \%(12 / 13)$ of patients the bleeding stopped after surgery.

\section{Discussion}

There are two non-surgical endoscopic evaluations of the small bowel presently available. ${ }^{12}$ 'Push' enteroscopy also called 'extended upper intestinal endoscopy,' is a procedure in which a long endoscope is passed orally and pushed beyond the ligament of Trietz. Though specialised instruments have been made for this examination, ${ }^{6-8}$ most experience has been with an adult or paediatric colonoscope passed orally. ${ }^{9-14}$ With these standard instruments it is possible to intubate the jejunum approximately $60 \mathrm{~cm}$ beyond the ligament of Trietz. Small bowel enteroscopy, also called sonde enteroscopy, relies on peristalsis to carry the long flexible endoscope to the distal small bowel. +51516 These instruments have no therapeutic capability nor tip deflection and examination is made upon withdrawal of the instrument.

Enteroscopy is useful in determining the site of blood loss in patients with obscure gastrointestinal bleeding. Push enteroscopy successfully diagnoses the cause of bleeding in 13-46\% of these patients. ${ }^{11-1+}$ It is notable that five of the 13 small bowel tumours reported in this series were found during 'push' enteroscopy, which requires no specialised instrument and is routinely available. The early performance of push enteroscopy in patients with obscure bleeding is recommended. Small bowel enteroscopy is also useful for the patients with obscure bleeding, and experience with this instrument has shown a yield of $26-33 \% .^{31718}$ In this reported series, a diagnosis was made in $50 \%$ of patients. Arteriovenous malformations were the most 
common finding, accounting for $80 \%$ of causes discovered. Small bowel tumours were the second most common cause of obscure gastrointestinal bleeding, accounting for $10 \%$ of findings or $5 \%$ of all patients. This is similar to the $7 \%$ incidence described by Thompson et al. ${ }^{19}$ In other series of patients with small bowel tumours obscure bleeding was also often the only presenting symptom, which contributed to the difficulty in establishing the diagnosis. Bleeding as the presenting complaint occurs in $25-53 \%$ of patients with small bowel tumours. ${ }^{20-22}$ Since the sole presentation of a small bowel tumour may be obscure bleeding the diagnosis is often delayed, contributing to the poor prognosis in patients with malignant small bowel tumours. ${ }^{23} 24$

Routine small bowel series and angiography may not detect small bowel tumours. ${ }^{25-27}$ Enteroclysis is a double contrast study of the small bowel, performed using barium and methylcellulose as contrast agents injected through a tube passed orally into the duodenum. Enteroclysis has been recommended for patients with suspected small bowel tumours, since the diagnostic yield may be as high as $10 \%$ of patients with obscure gastrointestinal bleeding. ${ }^{27}$ Even a carefully performed enteroclysis may miss a small bowel tumour, as shown by the neoplasms we found in patients with negative $x$ ray studies.

Small bowel enteroscopy permits direct visual examination of the small bowel, but this visualisation is not complete. The instrument is limited in its mucosal visualisation, secondary to the lack of total small bowel intubation in all examinations, the lack of tip deflection capability, and occasional uncontrolled instrument withdrawal. Approximately $50-70 \%$ of small bowel mucosa is observed during a standard examination according to previous estimates. ${ }^{3}$ Early evaluation of small bowel enteroscopy suggested that the examination may miss isolated, non-actively bleeding polyps or tumours of the small bowel. This has occurred in two young patients with normal enteroscopy who were referred for exploratory laparotomy because of continuing obscure bleeding and were found to have a small bowel tumour. In one, a leiomyoma was missed in the jejunum, and in the second, the lesion was not reached by the enteroscope.

Patients with small bowel tumours are relatively young compared with patients with other causes of obscure gastrointestinal bleeding. The mean age of our patients with small bowel tumours was 51 years, which is similar to that in previous reports. ${ }^{202829}$ The difference encountered in transfusions between the younger small bowel tumour patients and the older patients with arteriovenous malformations may not be an independent variable but may correlate with the patient's age, as younger patients can tolerate anaemia generally better than older patients.

We agree with Thompson et al who recommend that young patients with persistent obscure blood loss should be referred for early exploratory laparotomy. ${ }^{25}$ In their series of 37 patients with obscure bleeding, only one of 15 patients under age 50 had a small bowel lesion not detected by exploratory laparotomy alone. Seven of 19 patients over 50 required angio- graphy or endoscopy of the small bowel preoperatively to diagnose the source of the bleeding. This variation is secondary to the high incidence of small bowel tumours and Meckel's diverticula in the younger patients and the greater incidence of arteriovenous malformations in the older patients.

We conclude that small bowel enteroscopy may be diagnostic of small bowel tumours even when all previous diagnostic studies, including enteroclysis and angiography, are negative. Earlier concerns with the present state of endoscopic instrumentation suggesting that enteroscopy may not be diagnostic for isolated tumours seems less important.

1 Tada M, Kawai K. Small bowel endoscopy. Scand $\mathcal{f}$ Gastroenterol 1984; 19 (suppl 102): 39-52.

2 Lewis BS, Waye JD. Enteroscopy in 1988: pros and cons. Am 7 Gastroenterol 1988; 83: 799-802.

3 Lewis BS, Waye JD. Chronic gastrointestinal bleeding of obscure origin. Role of small bowel enteroscopy. Gastroenterology 1988; 94: 117-20.

4 Tada M, Shimizu S, Kawai K. A new transnasal sonde-type fiberscope (SSIF VII) as a panenteroscope. Endoscopy 1986 18: $121-4$

5 Lewis BS, Waye JD. Total small bowel enteroscopy. Gastrointest Endosc 1987; 33: 435-8.

6 Ogoshi K, Hara Y, Ashizawa S. New technique for small intestinal fiberoscopy. Gastrointest Endosc 1973; 20: 64-5.

7 Morishita T, Hibi T, Asakura H. Endoscopy of the jejunal mucosa in human cholera. Gastrointest Endosc 1978; 24: mucosa

8 Hibi T, Asakura H, Kobayashi K, et al. Alpha heavy chain disease lacking secretory alpha chain with cobblestone appearance of the small intestine and duodenal ulcer demonstrated by endoscopy. Gut 1982; 23: 422-7.

9 Parker H, Agayoff J. Enteroscopy and small bowel biopsy utilizing a peroral colonoscope. Gastrointest Endosc 1983; 29: $139-40$.

10 Barkin J, Schonfeld W, Thomsen S, et al. Enteroscopy and of small bowel disease. Gastrointest Endosc 1985; 31: 215-7.

11 Foutch P, Sanowski R, Kelly S. Enteroscopy, a method for detection of small bowel tumors. Am $\mathcal{J}$ Gastroenterol 1985 ; 80: $887-90$.

12 Lewis B, Waye J. Small bowel enteroscopy: a comparison of findings with push and sonde enteroscopy in 81 patients with GI bleeding of obscure origin. Gastrointest Endosc 1988; 34 207.

13 Foutch PG, Sawyer R, Sanowski R. Enteroscopy can alter the course of difficult patients with GI bleeding. Gastrointes Endosc 1989; 35: 193

14 Messer J, Romeu J, Waye J, Dave P. The value of proxima jejunoscopy in unexplained gastrointestinal bleeding. Gastrointest Endosc 1984; 30: 151 .

15 Tada M, Akasaka Y, Misaki F, et al Clinical evaluation of a sonde-type small intestinal fiberscope. Endoscopy 1977; 9 . 33-8.

16 Tada $M$, Misaki F, Kawai K. Pediatric enteroscopy with sonde-type small intestinal fiberscope (SSIF VI). Gastrointes Endosc 1983; 29: 44-7.

17 Barthel J, Vargo J, Sivak M. Assisted passive enteroscopy and gastrointestinal tract bleeding of obscure origin. Gastrointest Endosc 1990; 36: 222.

18 Gostout C, Schroeder K, Burton D. Small bowel enteroscopy: an early experience in GI bleeding of unknown origin. Gastrointest Endosc 1990; 36: 219.

19 Thompson JN, Salem RR, Hemingway AP. Specialist investigation of obscure gastrointestinal bleeding. Gut 1987; 28 47-51.

20 Darling RC, Welch CE. Tumors of the small intestine. $N E n g$ 7 Med 1959; 260: 397-407.

21 Wilson JM, Melvin DB, Gray GF, Thorbjarnarson B. Benign small bowel tumors. Ann Surg 1985; 181: 247-50.

22 Wilson JM, Melvin DF, Gray GF, Thorbjarnarson B. Primary malignant tumors of the small bowel. Ann Surg 1975; 180 $175-9$.

23 Coutsoftides T, Shibata HR. Primary malignant tumors of the small intestine. Dis Colon Rectum 1979; 22: 24-6.

24 Gupta S, Gupta S. Primary tumors of the small bowel. A clinicopathologic study of 58 cases. I Surg Oncol 1982; 20: 161-7.

25 Thompson JN, Hemingway AP, McPherson GAD, et al Obscure gastrointestinal haemorrhage of small bowel origin. BMF 1984; 288: 1663-5.

26 Martin LF, Max MH, Richardson JD, Peterson GH. Small bowel tumors: continuing challenge. South Med F 1980; 73: 981-5.

27 Rex DK, Lappas JC, Maglinte DDT. Enteroclysis in the evaluation of suspected small intestinal bleeding. Gastroenterology 1989; 97: 58-60.

28 Maglinte DDT, Elmore MF, Chernish SM, et al. Enteroclysis in the diagnosis of chronic unexplained gastrointestina bleeding. Dis Colon Rectum 1982; 28: 403-62.

29 Treadwell TA, White RR. Primary tumors of the small bowel. Am f Surg 1975; 130: 749-55. 